\title{
SOBRE A RELAÇÃO DA LÓGICA COM A ONTOLOGIA EM HEGEL. NOTAS PARA UMA DISCUSSÃO DA INTERPRETAÇÃO DE REDDING
}

\author{
Federico Orsini $^{1}$
}

\begin{abstract}
Resumo:
O objetivo do presente artigo é examinar as pressuposições de uma recente interpretação de Redding acerca da relação da Lógica com a Ontologia em Hegel. Especificamente, pretendo questionar: (i) o modo em que Redding reconstrói as linhas de continuidade e de descontinuidade entre Aristóteles, Kant e Hegel; (ii) a interpretação da dialética de Hegel em termos de uma pragmática do uso linguístico; (iii) a explicação da objetividade do pensamento por meio das noções de intencionalidade, realismo e falibilismo; (iv) o critério de distinção entre Lógica Objetiva e Lógica Subjetiva na Ciência da Lógica de Hegel. Minha conclusão é que a ontologia, enquanto teoria do ser, somente pode se justificar para Hegel enquanto lógica, a qual constitui a ciência do ser enquanto ser pensado. Todavia, o caráter dialéticoespeculativo da Lógica hegeliana não admite uma abordagem transcendental no sentido kantiano ou neotranscendental, porque essa mesma abordagem é vulnerável a objeções céticas de tipo radical, objeções que uma lógica dialética pretende incorporar ao caminho de apresentação autocrítica das categorias.
\end{abstract}

Palavras-chave: Lógica. Ontologia. Pressuposição. Transcendental. Objetividade.

\section{ON THE RELATION OF LOGIC TO ONTOLOGY IN HEGEL. NOTES FOR A DISCUSSION OF REDDING'S INTERPRETATION}

\begin{abstract}
:
The aim of this article is to examine the presuppositions of Redding's interpretation of the relation of logic to ontology in Hegel. Specifically, I will challenge the following points: (i) the way Redding reconstructs the continuities and discontinuity between Aristotle, Kant and Hegel; (ii) the interpretation of Hegel's dialectic in terms of a pragmatics of linguistic use; (iii) the explanation of the objectivity of thinking by way of the notions of intentionality, realism and fallibilism; (iv) the criterion for the distinction between Objective and Subjective Logic in Hegel's Science of Logic. My claim is that ontology (theory of being) can only be justified for Hegel in the form of logic as the science of being as being that is thought. However, the dialectical and speculative character of Hegel's Logic does not admit any transcendental or quasi-transcendental approach, because the latter falls prey to radical skeptical objections. Differently from Kant's transcendental logic, Hegel's dialectical logic lays claim to incorporate this kind of objections into the path of the self-critical presentation of categories.
\end{abstract}

Keywords: Logic. Ontology. Presupposition. Transcendental. Objectivity.

\section{Introdução}

Por mais diversamente que se interpretem os detalhes da revolução kantiana e seus efeitos na história da filosofia, a questão mais fundamental que ela nos legou é a seguinte: Por que uma explicação crítica das categorias do ser tem que ser inseparável de uma explicação crítica das categorias do pensar?

\footnotetext{
1 Doutor em Filosofia pela Universidade de Padova (Itália); Professor Colaborador do Programa de Pós-
} Graduação em Filosofia da PUCRS, Bolsista PNPD CAPES. Endereço: platoniet@yahoo.it 
Numa contribuição recente sobre essa questão, Paul Redding argumentou que a metafísica de Hegel pretende, de alguma maneira, fundamentar-se na Lógica, e que o modo dessa fundamentação é uma inversão quase-kantiana daquela relação da lógica com a ontologia que se encontra na abordagem realista de Aristóteles. A alternativa em jogo seria a seguinte: por um lado, Aristóteles vê as categorias como estruturas pré-dadas do ser, que a alma humana seria capaz de simplesmente acolher e expressaria em si mesmas, sem ser assolada por algum tipo de problema de acesso epistêmico a um suposto 'mundo externo', visto que a alma é parte integral da natureza (physis) que ela mesma investiga; por outro lado, Kant concebe as categorias como estruturas autoconstituídas da razão humana, a qual, porém, seria incapaz de conhecer por si mesma a estrutura de qualquer realidade em si, isto é, independente dos interesses e das regras próprias da razão. De acordo com a perspectiva de Redding, O passo de Hegel para além de Kant "pode ser lido como uma tentativa de mostrar de que modo, apesar de cada um estar fundamentalmente limitado e condicionado em suas capacidades cognitivas, somos capazes de ultrapassar, de alguma maneira, esses limites em virtude de uma capacidade para a razão conceitual, baseada socialmente".2

No que se segue, pretendo examinar as pressuposições da interpretação de Redding. Especificamente, pretendo questionar: (i) o modo em que Redding reconstrói as linhas de continuidade e de descontinuidade entre Aristóteles, Kant e Hegel; (ii) a interpretação da dialética de Hegel em termos de uma pragmática do uso linguístico; (iii) a explicação da objetividade do pensamento por meio das noções de intencionalidade, realismo e falibilismo; (iv) o critério de distinção entre Lógica Objetiva e Lógica Subjetiva na Ciência da Lógica de Hegel.

\section{A reconstrução equivocada da relação de Hegel com Kant e com Aristóteles}

Redding alega que a abordagem hegeliana da metafísica ${ }^{3}$ tem que ser entendida no horizonte de uma dimensão kantiana. Isso quer dizer que Hegel inverteria

2 Cf. REDDING, P. The Relation of Logic to Ontology in Hegel, in Categories and Being. Essays on Metaphysics and Logic, eds. L.Haaparanta and J.Koskinen, Oxford University Press, 2012, pp.145166: "can be read as an attempt to show how, while we are each fundamentally limited and conditioned in our cognitive capacities, we are nevertheless capable of somehow going beyond those limits in virtue of a socially based capacity for conceptual reason" (tradução minha, p.147).

Vale destacar que o discurso de Redding sobre 'metafísica' não é unívoco. Pelo que o artigo mencionado deixa entender, Redding usa o termo 'metafísica' em três sentidos distintos: (i)

\begin{tabular}{|l|l|l|l|l|}
\hline Qonista Dialectus & Ano 5 & n. 12 & Janeiro - Julho 2018 & p. 419-438 \\
\hline
\end{tabular}


a relação da lógica com a ontologia que estava presente em Aristóteles: "enquanto que Aristóteles tenta explicar as categorias usadas ao pensar e falar sobre o mundo em termos das estruturas básicas do ser, a estratégia copernicana de Kant dá a prioridade explicativa às estruturas de nossos juízos sobre o mundo, e, então, deriva as correspondentes estruturas categorias a partir da maneira em que pensamos e falamos sobre o mundo" (tradução minha) ${ }^{4}$. A relação de Hegel com a ontologia de Aristóteles (entendida como "category theory") deveria ser concebida como uma negação determinada. O que Hegel conserva da teoria aristotélica das categorias é seu núcleo substancial, isto é, a ideia de que as estruturas de nosso pensamento e de nossa fala sobre o mundo não estão contrapostas ao mundo, mas sim revelam as estruturas inerentes ao mundo. O que Hegel nega dessa teoria são suas "residuais suposições dogmaticamente metafísicas, responsáveis pela negação kantiana dela".5

A meu ver, essa interpretação contém alguns problemas. Em primeiro lugar, Redding equivoca a relação entre Aristóteles e Kant, na medida em que ele não percebe que a derivação das estruturas do ser a partir do modo em que nós (seres humanos ou seres racionais finitos) pensamos e falamos sobre o mundo é exatamente aquilo que a teoria aristotélica das categorias pretendia fazer. Nesse sentido, a reconstrução de Redding da inversão kantiana da teoria aristotélica subestima o que elas têm em comum,

'metafísica' como semântica, quer dizer, como a investigação de como as estruturas mais básicas do pensamento, enquanto articuladas linguisticamente, revelam as estruturas mais básicas do 'mundo', ou seja, do conjunto de objetos que existem independentemente de nosso pensamento; (ii) 'metafísica' como a caricatura do dogmatismo, a saber, como a "visão da totalidade das coisas como uma supermente autorreferencial, cujos pensamentos não precisam e não podem sair de si mesmos" (p. 162, tradução minha); (iii) 'metafísica' como a ideia de que há "um sentido em que a vida da mente é imanente ou emerge da concepção hegeliana do mundo, a qual, de alguma forma, é orgânica" (p. 159, tradução minha). Redding extrai esse terceiro significado de Beiser, ao qual ele atribui a tentativa de derivar o conteúdo lógico a partir de um "tipo de filosofia metafísica da natureza" (p. 159), onde o adjetivo 'metafísica' está, grosso modo, por 'assumido dogmaticamente como independente da lógica'. A interpretação de Redding pretende reconciliar o primeiro e o terceiro sentido de metafísica, derivando a metafísica orgânica de Hegel a partir do "desenvolvimento imanente de um conteúdo para a Lógica" (p. 159). A meu ver, tanto a interpretação quase-espinosista de Beiser quanto aquela logicista de Redding da relação entre Lógica e Metafísica em Hegel são acometidas por formas opostas de cripto-fundacionalismo, as quais, em última instância, são incompatíveis com o entendimento hegeliano do desenvolvimento imanente do conteúdo lógico.

4 "While Aristotle attempts to explain the categories used in thinking and talking about the world in terms of the basic structures of being, Kant's Copernican strategy gives explanatory priority to the structures of our judgments about the world, and then derives the corresponding "categorical" structures from the way we think and talk about it" (p. 147). Essa concepção remete à interpretação neo-transcendental defendida por Pippin, segundo o qual o idealismo de Hegel não é uma teoria sobre aquilo que é, mas sim uma teoria sobre os esquemas conceituais que possibilitam o próprio juízo humano e a formação de objetos possíveis do juízo. Cf. PIPPIN, R. Hegel's Idealism. The Satisfactions of Self-Consciousness. Cambridge: Cambridge University Press, 1989, pp. 243-250.

5 REDDING, P. (2012): "residual dogmatically metaphysical assumptions responsible for Kant's denial of it" (tradução minha, p. 147).

\begin{tabular}{|l|l|l|l|l|}
\hline Qevista Qialectus & Ano 5 & n. 12 & Janeiro - Julho 2018 & p. 419-438 \\
\hline
\end{tabular}


a saber, a possibilidade de derivar as estruturas do mundo a partir das formas da predicação no juízo ${ }^{6}$. O que diferencia Aristóteles de Kant não é a prioridade explicativa do ser sobre o juízo ou vice-versa, mas, antes, aquelas que, para Kant, são duas pressuposições injustificadas de Aristóteles: o isomorfismo entre pensamento/juízo e realidade; (ii) o caráter rapsódico (isto é, não científico) da enumeração aristotélica das categorias, ou seja, a falta de um fio condutor para a derivação exaustiva delas. Precisamente essa exigência de derivação ou gênese das categorias é o que une Kant e Hegel e, ao mesmo tempo, distingue ambos da admissão aristotélica de uma multiplicidade imediata (isto é, não derivável) de categorias.

Em segundo lugar, Redding acaba equivocando a posição de Kant, na medida em que ele identifica imediatamente subjetividade e razão, bem como identifica o idealismo transcendental, que é uma tese peculiar sobre a idealidade do espaço e do tempo, com o criticismo, o qual designa um autoexame abrangente da razão no que diz respeito a todas suas fontes e aos fins essenciais do conhecimento e da ação. Fazendo isso, Redding transforma Kant num precursor de Nietzsche, tecendo um fio direto entre o criticismo e o perspectivismo ou qualquer hermenêutica da finitude do século XX. Por causa disso, Redding deixa de lado o fato de que a primeira Crítica de Kant pretende fundamentar o conhecimento da objetividade, quer dizer, a universalidade e necessidade do sistema formal da natureza, e que, para tanto, as categorias não são concebidas como uma nossa propriedade (como nossas maneiras gerais de pensar e falar sobre o mundo), mas formas-conteúdos, produtos gerados espontaneamente pela razão, a qual encontra

\footnotetext{
Sobre esse ponto de semelhança entre Aristóteles e Kant e sua diferença do método hegeliano de derivação das categorias, ver: LAU, C.-F. "The Aristotelian-Kantian and Hegelian Approaches to Categories", The Owl of Minerva, 40:1 (2008-2009), pp.77-114. A alternativa entre uma ontologia que privilegia a forma proposicional e uma ontologia dialética foi destacada também por DÜSING, K.: Hegel e l'antichità classica, Napoli: Città del Sole, 1998, pp. 13-75; "Grundformen der Ontologie bei Kant und bei Hegel", Quaestio, 9 (2009), pp.311-324. Cabe destacar que a ênfase kantiana sobre o caráter proposicional da síntese a priori nos juízos foi questionada por FERRARIN, A. The Powers of Pure Reason. Kant on the Idea of Cosmic Philosophy. Chicago: Chicago University Press, 2015, pp. 126-7. Através de uma crítica interna a Kant, o autor enuncia três razões para não equiparar a síntese a priori com a forma do juízo, razões que se resumem à ideia de preservar o requisito de universalidade expresso pela síntese a priori. De fato, a expressão "síntese a priori" se aplica a todas as instâncias de extensão a priori para além de um conceito dado, enquanto o "juízo" não tem o mesmo alcance. Tendo em vista essa crítica, o ponto de semelhança entre Kant e Aristóteles pode resultar um tanto superficial, pois esconde duas concepções profundamente diversas da razão. Todavia, isso não confirma necessariamente a tese de Redding de que Hegel seria um seguidor de Kant, como é mostrado pela sua crítica à dedução kantiana das categorias a partir das formas do juízo e sua apropriação especulativa do tema da síntese a priori.
}

\begin{tabular}{|c|c|c|c|c|}
\hline Rovista Dialectus & Ano 5 & n. 12 & Janeiro - Julho 2018 & p. $419-438$ \\
\hline
\end{tabular}


os veículos de sua expressão discursiva nos juízos formulados por sujeitos humanos potencialmente racionais e autoconscientes.

Em terceiro lugar, Redding equivoca a relação de Hegel com Aristóteles sob dois aspectos relevantes. Primeiro, ele reduz a teoria aristotélica do ser à teoria das categorias, desconsiderando que o ser segundo as categorias constitui apenas um dos significados principais do ser para Aristóteles. Os outros são: o ser como acidente, o ser enquanto ato e potência, o ser como verdade. Todos esses significados, especialmente o significado do ser como atividade e potência, resultam extremamente relevantes para a apropriação hegeliana do legado aristotélico. Redding fala de "residual dogmatically metaphysical assumptions" por parte de Aristóteles, mas não fornece nenhuma explicação ulterior sobre o suposto dogmatismo de Aristóteles. A meu ver, isso depende do fato de que Redding confunde a metafísica dos gregos com a metafísica escolástica alemã, cujo procedimento dogmático é criticado detalhadamente sob o item "Primeira posição do pensamento a respeito da objetividade" do Conceito Preliminar da Enciclopédia (Enc. §§27-36).

Mas a metafísica escolástica alemã é um empreendimento da época moderna; como tal, ela é afetada por um conjunto de pressuposições que pertencem à filosofia da reflexão e que eram desconhecidas tanto a Platão quanto a Aristóteles ${ }^{7}$.

A porção do argumento em que Redding tenta mostrar a dimensão kantiana da abordagem hegeliana à teoria das categorias não explica por que Hegel deveria endossar a suposta inversão kantiana da abordagem aristotélica. Essa explicação não está claramente presente no artigo em discussão, mas é oferecida por uma obra anterior, onde Redding discute mais detalhadamente sua intepretação da 'metafísica' de Hegel em termos de uma semântica inferencialista ${ }^{8}$. O autor australiano pretende mostrar que a abordagem metafísica de Hegel é lógica porque ela ambiciona neutralizar a oscilação entre dois polos que moldaram de maneira oposta o problema da relação entre categorias e realidade: o polo do realismo de Aristóteles e o polo do idealismo de Kant.

7 Cf. HEGEL, G.W.F. Enciclopédia das Ciências Filosóficas em Compêndio (1830). Vol. I: A Ciência da Lógica (tradução de Paulo Meneses). São Paulo: Edições Loyola, 1995, p. 94: "Essa metafísica não era um pensar livre e objetivo, pois não deixava o objeto determinar-se livremente a partir de si mesmo, mas o pressupunha como já pronto. No que toca ao livre pensar, a filosofia grega pensava livremente, mas a escolástica não, já que recebia seu conteúdo igualmente como um conteúdo dado e, na verdade, dado pela Igreja” (Enc. §31 Adendo).

Refiro-me ao livro: REDDING, P. Analytic Philosophy and the Return of Hegelian Thought. Cambridge: Cambridge University Press, 2007.

\begin{tabular}{|l|l|l|l|l|}
\hline Q Povista Dialectus & Ano 5 & n. 12 & Janeiro - Julho 2018 & p. 419-438 \\
\hline
\end{tabular}


Hegel seria um crítico do "positivismo metafísico" que estaria implícito em cada um desses polos, quer dizer, da ideia de que o mundo revelado ou constituído pelas categorias seria um mundo de substâncias autossuficientes ou coisas em si, as quais ou são imediatamente acessíveis a nosso desejo ingênuo de saber (Aristóteles) ou se subtraem de nossos esquemas conceituais, os quais nos possibilitam conhecer apenas fenômenos (Kant). O motivo que teria conduzido Hegel a estar ao lado de Kant contra Aristóteles é a suposta convicção hegeliana de que a estrutura do ser mostra a si mesma dentro da estrutura lógica de nossos enunciados sobre entes particulares, entendendo por estrutura lógica um conjunto de características formais que articulam as relações inferenciais entre nossos enunciados ${ }^{10}$. Essa explicação do suposto kantismo de Hegel empenha Redding a um conjunto de teses sobre o significado do projeto lógico de Hegel. No que se segue, pretendo avaliar essas teses como outras tantas pressuposições questionáveis da atualização de Redding.

\section{Primeira pressuposição: A metafísica de Hegel como semântica}

Interpretar a metafísica de Hegel como uma semântica implica se comprometer com a tese de que o problema central da Lógica é justificar a maneira em que o pensamento obtém um conteúdo representational, ou seja, a investigação de como os conceitos - já tomados imediatamente como uma pluralidade - referem-se a um mundo supostamente externo a eles. A pressuposição questionável de Redding consiste precisamente em considerar o pensar em jogo na Lógica como um tipo de pensar que se refere a algo, que é sobre objetos. Sob esse aspecto, a interpretação de Redding atribui imediatamente à Lógica de Hegel a questão que constitui o âmago do mito fundador da filosofia analítica ${ }^{11}$ : até que ponto nossas representações do mundo, as quais incluem a linguagem e o pensamento, permitem lançar uma ponte para o próprio mundo? Para essa forma de filosofar, é óbvio e incontroverso que o pensamento é uma nossa propriedade mental ou linguística e que nossos estados mentais, bem como a linguagem em geral, são sobre o mundo. Para Hegel, ao contrário, a Lógica não "trata de um

9 REDDING (2007) pp. 223-36.

${ }^{10}$ REDDING (2007) p.232.

${ }^{11}$ Para uma avaliação crítica do mito fundador da filosofia analítica, bem como sobre os pontos de aproximação e de diferença entre hegelismo e filosofia analítica, ver a coleção de ensaios: NUZZO, A. (Org.) Hegel and the Analytic Tradition. New York: Continuum, 2009, especialmente pp.1-11.

\begin{tabular}{|l|l|l|l|l|}
\hline Q Povista Dialectus & Ano 5 & n. 12 & Janeiro - Julho 2018 & p. 419-438 \\
\hline
\end{tabular}


pensar sobre algo, que estaria por si mesmo, no fundamento, fora do pensar...mas as formas necessárias e as próprias determinações do pensar são o conteúdo e a própria verdade suprema" ${ }^{\prime 2}$.

Em outras palavras, aquilo que aparece óbvio para uma semântica, envolve, para a Lógica, uma concepção pressuposta da relação entre sujeito e objeto, a qual tem que ser abandonada antes de acessar o ponto de vista dialético-especulativo. Tornar de imediato o pensar um processo subjetivo de tipo consciencial, ou interpretar a Lógica à luz de um problema estritamente semântico, equivale a perder de vista a distinção hegeliana entre o conceito, que é atividade pura e simples, tanto subjetiva quanto objetiva, e a representação, que é a forma do pensamento de alguém sobre algo determinado. A meu ver, a tarefa que Hegel atribui Lógica é a explicação imanente de como o conceito tout court se articula em conceitos determinados ou formas que constituem dinamicamente tanto a estrutura do ser quanto a estrutura de nosso conhecimento do ser. No sistema da filosofia real (filosofia da natureza e filosofia do espírito), trata-se de entender como o conceito se instancia na esfera inconsciente da natureza e como se reconhece progressivamente na esfera do espírito. Em ambos os casos, a questão é entender a maneira de ser da natureza e a maneira de ser do espírito, não apenas aquela de justificar enunciados empíricos sobre a natureza ou sobre o espírito. A questão de como fundamentar a referência das representações a um suposto 'mundo externo' existe no sistema apenas como capítulo daquela parte da filosofia do espírito subjetivo que deve dar conta de como o espírito pressupõe a natureza e, simultaneamente, nega a aparência de dadidade e exterioridade da mesma. Fora do sistema, o problema da referência à realidade por meio de representações aparece como o problema do ceticismo moderno, o qual se baseia em pressuposições dogmáticas desconhecidas à forma de ceticismo antigo de tipo pirrônico. A Fenomenologia do Espírito visa justamente dissolver o quadro da epistemologia moderna tradicional através da retomada sistemática do problema cético do critério, aplicado a padrões de verdade internos à consciência comum, e da dissolução de pontos de vistas não científicos do saber ${ }^{13}$.

12 HEGEL, G.W.F. Ciência da Lógica. 1. A Doutrina do Ser. Petrópolis: Vozes, 2016, p. 53.

Sobre a relação entre Fenomenologia e ceticismo pirrônico, ver: FORSTER, M. Hegel and Skepticism. Cambridge: Harvard University Press, 1989, pp. 97-170; HEIDEMANN, D. Der Begriff des Skeptizismus. New York: De Gruyter, 2007, pp. 199-271; TRISOKKAS. I. Pyrrhonian Skepticism and Hegel's Theory of Judgment. Leiden: Brill, 2012, pp. 71-92.

\begin{tabular}{|c|c|c|c|c|}
\hline Revista Qialectus & Ano 5 & n. 12 & Janeiro - Julho 2018 & p. $419-438$ \\
\hline
\end{tabular}




\section{Segunda pressuposição: A objetividade do pensar como processo de tentativa e erro}

A segunda pressuposição questionável é a interpretação da noção de objetividade do pensamento, entendida em termos de uma independência do mundo de nossas capacidades cognitivas, as quais podem ou não acertar as estruturas das coisas: "Hegel está certamente de acordo com a ideia de que, nos juízos, os conceitos se aplicam, em última instância, a algo externo ao pensamento, porque aqui [scil. na Lógica Subjetiva] "conceito" e "objeto" são entendidos no sentido subjetivo. Os conceitos aplicados a objetos, ou os pensamentos concebidos sobre os mesmos, são os conceitos e os pensamentos de sujeitos particulares, finitos, e a corrigibilidade destes testemunha a independência daquilo sobre o qual eles são". ${ }^{14}$

Agora, se tudo isso pode valer de um ponto de vista realista, o qual toma como dada e garantida a separação entre mente e mundo, não se pode dizer que o mesmo vale para a compreensão da objetividade na Lógica. Decerto, 'objetividade' demonstra ter vários significados no pensamento de Hegel, mas a expressão "pensar objetivo" "15 significa mais do que um tipo de pensar que assegura a exatidão de asserções sobre objetos empíricos. As expressões objetives Denken ou objektive Gedanken (pensamentos objetivos, Enc. §24) foram cunhadas por Hegel ${ }^{16}$ para desafiar a unilateralidade do ponto de vista da modernidade, a qual considera o pensar exclusivamente como uma faculdade subjetiva dentre as outras. Em seu sentido especulativo, 'objetividade' indica, para Hegel, a atuação do conceito na esfera externa de sua realidade determinada, na medida em que esta se torna meio de expressão progressivamente adequada das formas estruturais da subjetividade (conceito, juízo, silogismo). Num sentido ainda mais radical, a objetividade não é somente uma forma de alteridade momentânea do conceito, mas um sinônimo de verdade enquanto ser em si e para si do todo. Nesse sentido, a objetividade não é mais um termo relativo ou oposto,

14 REDDING (2012) p. 163 (tradução minha).

15 HEGEL (2016) p. 50, p. 53.

16 Sobre o tema do pensar objetivo em Hegel, ver: HALBIG, C. Objektives Denken. Erkenntnistheorie und Philosophy of Mind in Hegels System, Stuttgart - Bad Canstatt, 2002; ILLETTERATI, L. (Org.) L'oggettività del pensiero. La filosofia di Hegel tra idealismo, anti-idealismo e realismo. Trento: Verifiche, 36, 2007; BRINKMANN, K. Idealism without Limits. Hegel and the Problem of Objectivity. Dordrecht-New York: Springer, 2010; FERRARIN, A. Il pensare e l'io. Hegel e la critica di Kant. Roma: Carocci, 2016, pp. 70-140.

\begin{tabular}{|c|c|c|c|c|}
\hline Qenista Dialectus & Ano 5 & n. 12 & Janeiro - Julho 2018 & p. $419-438$ \\
\hline
\end{tabular}


porque a verdade não é uma correspondência entre duas esferas pressupostas como distintas, mas um processo absoluto (em si e para si) de manifestação do conceito em suas configurações determinadas.

Nesse sentido sistemático, a objetividade não diz respeito ao acesso empírico à realidade por meio de tentativas e erros, mas à necessidade de compreender as coisas à luz das determinações conceituais que lhes são imanentes. Se as determinações conceituais de uma coisa são equivocadas (se, por exemplo, entende-se o Estado à luz de determinações mecânicas), a falta de objetividade está no entendimento dos sujeitos finitos, não na essência da coisa. Inversamente, se a própria coisa é adequada ou não a seu conceito (por exemplo, se um Estado é racional ou irracional), isso depende da capacidade da própria coisa de superar ou sucumbir à própria finitude, ou de uma ruptura entre relações institucionalizadas objetivas e reivindicações das vontades subjetivas dos cidadãos, não de um erro meramente cognitivo de avaliação dos sujeitos que emitem juízos sobre a coisa. A concepção hegeliana da objetividade neutraliza a oposição entre idealismo e realismo, porque não faz a suposição prévia de que "pensar é uma expressão que atribui a determinação nela contida preferencialmente à consciência" ${ }^{\prime 17}$. Decerto, os juízos emitidos por entidades conscientes podem ser objetivos, mas não pelo fato de eles conterem as condições de possibilidade da experiência do objeto julgado, mas sim pelo fato de reconstruírem e trazerem à consciência a racionalidade objetiva que já age e se faz valer na coisa em questão.

\section{Terceira pressuposição: A interpretação pragmática da contradição}

A terceira pressuposição de Redding é sua apresentação da contradição dialética em termos de uma pragmática da linguagem. Redding admite que a contradição não é uma relação formal externa entre enunciados contraditórios ( $p \mathrm{v} \sim \mathrm{p})$, mas antes o marco do espaço lógico evolutivo traçado através de toda a Ciência da Lógica. Especificamente, a contradição dialética expressaria as transformações categoriais pelas quais nossa concepção da natureza dos objetos muda ao passarmos da esfera da percepção para a esfera da ciência. Na medida em que essa mudança ocorre dentro do conjunto de determinações de pensar da Lógica, a contradição surge sempre

${ }^{17}$ HEGEL (2016) p. 53.

\begin{tabular}{|l|l|l|l|l|}
\hline Q ovista Qialectus & Ano 5 & n. 12 & Janeiro - Julho 2018 & p. 419-438 \\
\hline
\end{tabular}


do contraste determinante de uma determinação com os outros membros desse conjunto, entendido como um espaço lógico de razões à maneira de Sellars. O motivo que conduz Redding a entender a dialética, isto é, o desenvolvimento do conteúdo lógico através de contradições, como uma pragmática do uso da linguagem é a tentativa de determinar a maneira em que o idealismo de Hegel busca uma saída do arcabouço teórico da epistemologia moderna, segundo a qual "todas as coisas mentais (conceitos, conhecimento, etc.) e todas as coisas mundanas (objetos, fatos, etc.) são concebidas como radicalmente separadas e, contudo, determinadas, e, então, suas relações são investigadas" "18. Para Redding, a saída de Hegel das aporias do representacionalismo equivale à ideia de fundamentar os processos cognitivos na "pragmática de jogos linguísticos baseados socialmente e governados por regras, pragmática que é central para sua noção de "espírito objetivo"”, 19 , ao invés que numa suposta relação direta entre mente e mundo.

Em suma, as pressuposições da compreensão da dialética de Hegel na leitura de Redding são as seguintes: (i) o espaço lógico das razões é, em seu fundamento real, um espaço social, o qual, segundo Pinkard e Brandom - autores de referência da interpretação de Redding - estabelece o significado das pretensões feitas por todos os agentes que participam no jogo de pedir e dar razões ${ }^{20}$; (ii) o reconhecimento, como interação bem sucedida entre os sujeitos sociais, é a fonte de legitimação do espaço social e constitui o fio condutor para o entender como Hegel explica a capacidade humana para o pensamento e a reflexão; (iii) os conceitos ganham seu conteúdo somente como predicados de juízos possíveis, numa tal maneira que entender um conceito equivale a saber como usá-lo numa variedade de juízos ${ }^{21}$.

18 REDDING (2012) p. 158 (tradução minha).

19 Ibid.

20 Para uma reconstrução exaustiva do contexto teórico das interpretações norte-americanas de Hegel, ver CORTI, L. Ritratti hegeliani. Un capitolo della filosofia americana contemporanea. Roma: Carocci, 2014.

21 Para o entendimento da questão da determinidade dos conceitos, Redding reconhece sua dívida com a ideia de Brandom de uma semântica pragmatista. Com respeito ao entendimento dos conceitos como predicados de um juízo possível, Redding está de acordo com a interpretação de Pippin, o qual propõe ler a Lógica de Hegel como uma continuação e um aprimoramento da lógica transcendental de Kant. Em sua resenha do livro de Redding, Brandom explicita seu entendimento de Hegel como holista semântico, lógico e metafísico, o qual defende uma "concepção não-psicológica do conceitual" como "o que quer que se mantenha em relações com o que ele [scil. Hegel] chamou de "determinação negativa" e "mediação" - pelas quais ele quer significar a incompatibilidade material e a consequência material”. (BRANDOM, R. "Hegel e a filosofia analítica", Veritas, v.56, n.1, 2011, pp.78-94, p. 84).

\begin{tabular}{|l|l|l|l|l|}
\hline Qenista Dialectus & Ano 5 & n. 12 & Janeiro - Julho 2018 & p. 419-438 \\
\hline
\end{tabular}


Como consequência desse conjunto de pressuposições, a dialética de Hegel é reduzida ao processo de encontrar soluções para casos de opiniões contrastantes, onde um sujeito diz "este A é F", enquanto outro diz "este A não é F". A oposição de afirmações e contrafirmações obriga a reflexão a buscar justificações que possam iniciar um procedimento de autocorreção. Desta maneira, o espaço lógico se amplia mediante um processo de negação determinada, até que o campo de investigação chega a incluir contextos de raciocínio cada vez mais largos (tais como os das ciências e dos sistemas lógicos) que permitem avaliar a validade de asserções ou inferências individuais. Para adquirir determinação, o espaço lógico precisa dar conta da exterioridade do mundo ou do espaço não lógico, sem, todavia, estar comprometido com a "imagem metafisicamente cética de um fosso intransponível entre conceito e mundo em si" ${ }^{\text {22 }}$. Redding persegue tornar compatíveis o requisito de exterioridade ${ }^{23}$ e a autonomia do espaço lógico: “o objeto singular julgado e o mundo ao qual ele pertence não estão além da esfera da conceitualidade, precisamente porque, ao predicar o conceito da coisa concreta em sua singularidade, o juiz se torna ciente de (põe) aquela coisa na determinação da singularidade, e, portanto, como externa [...] há qualquer razão para exigir algum sentido ulterior, mais forte, de exterioridade do mundo?"24.

A meu ver, essa reconstrução da contradição perde de vista a concepção distintivamente hegeliana do pensar objetivo e da dialética como lógica de autotransformação desse mesmo pensar. O primeiro problema consiste decorre da suposição de que o pensar objetivo formaria um espaço lógico, delimitado com respeito a outros tipos de espaços ou mundos (por exemplo, o espaço físico e o espaço das representações mentais). Para Hegel, o pensar objetivo não pode pertencer a um espaço ou ser elemento de um mundo, porque cada mundo é um conjunto finito e fechado em si mesmo de fenômenos, enquanto que o pensar, por ele se legitimar unicamente como processo de autodeterminação sem pressupostos externos, não pode se restringir a um espaço, mas tem que justificar a própria constituição da categoria de mundo e, além disso, da possibilidade real de qualquer mundo ou espaço que venha a se apresentar. $\mathrm{Na}$

22 REDDING (2012) p. 164.

23 O requisito de exterioridade tem uma articulação tripla: (i) exterioridade entre a coisa concreta e o conceito associado a ela por alguém que a julgue; (ii) exterioridade entre o conceito e qualquer juiz particular finito que estabeleça a conexão entre o objeto e o conceito; (iii) exterioridade entre os juízes, na medida em que eles estão numa situação dialética de conflito entre pretensões de verdade seguras de si.

24 REDDING (2012) p. 164.

\begin{tabular}{|c|c|c|c|c|}
\hline Q Rovista Dialectus & Ano 5 & n. 12 & Janeiro - Julho 2018 & p. $419-438$ \\
\hline
\end{tabular}


medida em que o elemento lógico (das Logische) tem que articular qualquer mundo e justificar as transições de um para outro, ele vai além do limite de qualquer um deles, e não pode, por isso, formar apenas um espaço lógico, limitado e contraposto ao espaço da objetividade efetiva e ao espaço da subjetividade mental. A pretensão de localizar o espaço do pensamento lógico é vulnerável à objeção cética de que não temos razões inabaláveis para determinar por que o pensar constitui apenas um mundo e não os outros, assim como, assumindo que o pensar lógico forme um espaço contraposto a outros, não temos explicações sobre por que o mundo das razões lógicas fundamentaria o mundo das práticas sociais ou vice-versa.

O segundo problema é o entendimento pragmático da contradição. Embora Redding rejeite um entendimento meramente proposicional da contradição, parece-me que seu entendimento fique preso a um arcabouço semântico e epistêmico no qual necessariamente se pressupõe que verdade, método e linguagem sejam construções humanas, demasiado humanas, distintas do mundo que elas buscam representar e controlar. Reduzindo a dialética hegeliana a um fenômeno social de conflito entre pretensões opostas de verdade, esvai-se a objetividade da contradição, a qual, para Hegel, é um fenômeno rigorosamente lógico e remete ao processo pelo qual, em geral, cada determinação do pensar mostra a diferença interna entre seu conteúdo finito e sua atividade de justificar a si mesma como determinação verdadeira (ou seja, completamente autoexplicativa). ${ }^{25}$

Além disso, o fato de que Redding não percebe a relevância do tema da unidade de crítica e apresentação das formas lógicas, negligenciando a fundamentação lógica (não meramente social) da objetividade, vai de mãos dadas com a falta de reconhecimento do sentido objetivo do juízo na Lógica. Para Hegel, o sentido subjetivo do juízo é aquele que o reduz a uma operação com a qual um sujeito finito atribui predicados a algo. Pelo contrário, a objetividade do juízo significa que "todas as coisas são um juízo - isto é, são singulares que são em si uma universalidade ou natureza interior; ou são um universal que é singularizado." (Enc. §167) ${ }^{26}$. Em outras palavras, para Hegel, os juízos são determinações ontológicas das coisas, não apenas

25 A literatura crítica sobre o problema de como entender a contradição dialética em Hegel é muito ampla. Para uma reconstrução equilibrada dos problemas ligados às principais interpretações (metafórica, crítico-negativa, ontológica) e uma defesa da concepção ontológica da contradição, remeto a: BORDIGNON, M. Ai limiti della verità. Il problema della contraddizione nella logica di Hegel. Pisa: ETS, 2014.

26 HEGEL (1995) p. 303.

\begin{tabular}{|c|c|c|c|c|}
\hline Qevista Dialectus & Ano 5 & n. 12 & Janeiro - Julho 2018 & p. $419-438$ \\
\hline
\end{tabular}


determinações de nosso saber sobre as $\operatorname{coisas}^{27}$, enquanto que Redding trata os juízos simplesmente como variedades, mais ou menos complexas, de afirmações feitas por qualquer sujeito particular, as quais estariam no controle da vontade do sujeito individual ou de uma comunidade social de sujeitos que julgam sobre a correção das afirmações individuais. De modo análogo, a objetividade do silogismo hegeliano é captada apenas parcialmente pela proposta de um "inferencialismo semântico", porque na Lógica de Hegel não se trata da questão de ser "um realista modal sobre o mundo objetivo (o mundo como ele é independentemente de sua relação com quaisquer atividades ou processos de pensamento) ${ }^{, 28}$, mas de reconhecer que todas as coisas são racionais somente enquanto sua articulação interna está estruturada de acordo com o nexo simultâneo de todas as determinações do conceito (universal, particular, singular). ${ }^{29}$

\section{Quarta pressuposição: A relação transcendental entre Lógica Objetiva e Lógica Subjetiva}

Por fim, a última pressuposição principal da interpretação de Redding concerne à transição da Lógica Objetiva (Doutrina do Ser e da Essência) para a Lógica Subjetiva (Doutrina do Conceito) dentro da Ciência da Lógica. O autor australiano entende a Lógica Objetiva como a teoria das categorias de Hegel, na qual as determinações do pensar "são consideradas igualmente como determinações que constituem a estrutura transcendental das coisas às quais o pensamento se refere (the transcendental structure of the things that thought is about) ${ }^{„ 30}$. A Lógica Subjetiva ainda "representa o equivalente hegeliano do conteúdo transcendental da lógica de Kant",31, mas de uma maneira que precisa justificar o ponto de vista reflexivo dos sujeitos finitos e suas tentativas de superar suas capacidades cognitivas finitas.

Ademais, a Doutrina do Ser conteria uma abordagem lógica baseada nos termos, enquanto que a Doutrina da Essência mostraria uma abordagem baseada em

27 Para uma reconstrução concisa da teoria hegeliana do juízo, remeto a: IBER \& ORSINI \& NARDI \& BAVARESCO. "Teoria do juízo na lógica do conceito de Hegel”. Revista Opinião Filosófica, Porto Alegre, v. 06; nº. 01, 2015, pp. 34-48.

28 BRANDOM, R. (2011) p. 84.

29 Sobre o significado da leitura ontológica do silogismo em Hegel, remeto a um trabalho meu: ORSINI, F. A teoria hegeliana do silogismo. Tradução e comentário. Porto Alegre: Editora Fi, 2016. Sobre os desafios de uma leitura 'ontológica' da Lógica de Hegel e um exame detalhado do estado da arte, permito-me remeter a: ORSINI, F. "Il problema dell'ontologia nella Scienza della logica di Hegel” (Tese de doutorado, Universidade de Padova, 2014).

30 REDDING (2012) p. 158.

31 Ibid.

\begin{tabular}{|l|l|l|l|l|}
\hline Q Povista Dialectus & Ano 5 & n. 12 & Janeiro - Julho 2018 & p. 419-438 \\
\hline
\end{tabular}


proposições, a qual seria mais adequada a expressar a estrutura da moderna visão científica do mundo. Em geral, a prossecução hegeliana da lógica transcendental kantiana constituiria uma mediação das características imediatas do pensamento antigo com as características mediadas ou reflexas introduzidas pelo pensamento moderno.

Essa interpretação da estrutura interna da Ciência da Lógica, além de oferecer uma imagem demasiadamente estilizada da diferença entre lógica antiga e moderna, reflete os traços da assim chamada visão neo-transcendental ${ }^{32}$, a qual lê a Lógica como um discurso feito de vários níveis. O primeiro nível é a esfera do ser, a qual tem a ver com as categorias em que o pensar apreende as coisas tais como elas são encontradas imediatamente, como objetos da percepção sensorial. O segundo nível é a esfera da essência, a qual estuda as categorias de relação em que as coisas estão presentes ao pensamento enquanto ele reflete sobre elas. O terceiro nível é a esfera do conceito, o qual finalmente torna explícita a atividade subjetiva pela qual as coisas são trazidas à forma que constitui o que elas significam para nós.

A meu ver, o cerne da leitura neo-transcendental consiste em três operações questionáveis. Em primeiro lugar, ela pressupõe que a Lógica de Hegel seja meramente uma continuação do projeto transcendental de Kant, ou seja, de um projeto que busca determinar as condições a priori da possibilidade da experiência. Fazendo essa pressuposição, ela descarta a natureza dialético-especulativa do projeto de Hegel e suas críticas à consideração transcendental do elemento lógico, críticas que se encontram expostas de maneira muito clara e explícita na Introdução geral à Ciência da Lógica. ${ }^{33}$ Em segundo lugar, a leitura neo-transcendental supõe que a finalidade principal da lógica dialético-especulativa seja o tratamento das várias maneiras ou dos esquemas conceituais com que o pensamento intencional, autoconsciente, lida com os objetos de juízos potencialmente conscientes. Desta maneira, ela não suspende a pressuposição de que o pensar seria desde o início a relação de um sujeito consciente a um objeto por

32 Os principais representantes dessa visão são: HARTMANN, K. "Hegel: A Non-Metaphysical View". Em: Hegel: A Collection of Critical Essays. MacIntyre A. (Org.). Notre Dame: Notre Dame Press, 1972, pp. 101-124; PINKARD, T. "The Logic of Hegel's Logic". The Journal of the History of Philosophy, 17, 1979, pp. 417-435; PIPPIN (1989); LONGUENESSE, B. Hegel and the Critique of Metaphysics. translated by Nicole J. Simek. Cambridge: Cambridge University Press, 2007.

33 Para uma crítica muito eficaz dessa leitura simplesmente continuísta da relação entre Kant e Hegel, ver especialmente: HOULGATE, S. The Opening of Hegel's Logic. Indiana: Purdue University Press, 2006, pp. 126-43; FERRARIN (2016) pp. 171-81. Sobre a natureza distintiva do projeto de Hegel, permito-me remeter a: ORSINI, F. "O projeto hegeliano de uma filosofia livre de pressuposições" (artigo aceito para a publicação pela revista Kriterion).

\begin{tabular}{|c|c|c|c|c|}
\hline Rovista Dinlectus & Ano 5 & n. 12 & Janeiro - Julho 2018 & p. $419-438$ \\
\hline
\end{tabular}


meio de um juízo e fica presa a uma dualidade entre esquema conceitual e conteúdo. Em terceiro lugar, a leitura transcendentalista considera a Lógica Objetiva como uma 'lógica-objeto' (referente a objetos e fatos) e a Lógica Subjetiva, como uma 'metalógica' ${ }^{, 34}$ que deve supostamente expor o esquema conceitual das condições de possibilidade para os pensamentos sobre os objetos, pensamentos que constituíam o conteúdo da Lógica Objetiva.

O que acho particularmente questionável na fala sobre lógica-objeto e metalógica é a representação da progressão lógica como uma espécie de edifício estruturado por níveis ou andares, dos quais o mais elevado seria a condição de possibilidade do inferior. A meu ver, essa imagem perde de vista o fato de que a Lógica é reflexiva ou autocrítica do início até o fim (não apenas na Doutrina do Conceito) e que a transição da Lógica Objetiva para a Lógica Subjetiva tem que ser imanente, ou seja, tem que ser feita a partir da reflexividade que já é implícita ou 'em si' na Lógica Objetiva. Pode-se certamente admitir que a Lógica de Hegel contenha níveis de complexidade crescente, mas tudo depende de entendermos esses 'níveis' como estágios dinâmicos e internamente entrelaçados, não como meras partes de um todo ou como andares de um edifício. Falar de 'metalógica' é redundante e desviante; é redundante, porque a Lógica hegeliana é por si mesma autorreflexiva; é desviante, na medida em que introduz uma margem de exterioridade e de transcendência entre o pensamento que investiga as formas lógicas e o pensamento que é o objeto da investigação. Todavia, essa exterioridade não pode existir para Hegel, porque na Lógica "as formas-de-pensamento devem ser consideradas em si e para si; são o objeto e a atividade do objeto mesmo; examinam-se a si mesmas, e devem determinar nelas mesmas seu limite e mostrar sua falha" (Enc. $\$ 41$ Adendo 1). ${ }^{35}$

Ademais, o termo 'transição' não é inócuo, porque designa a categoria dialética por excelência da Doutrina do Ser. Ela significa um devir e uma alteração pela qual cada determinação desaparece e passa para outra, sem que seja capaz de expressar o sentido de sua relação com aquela que entrou em seu lugar. Somente uma leitura linear da Lógica pode aplicar o pensamento da transição à relação entre Lógica Objetiva e Lógica Subjetiva. Uma maneira mais adequada de entender a imanência dessa relação

34 Cf. PINKARD (1979) p. 428; PIPPIN (1989) pp. 175-260.

35 HEGEL (1995) p. 109.

\begin{tabular}{|c|c|c|c|c|}
\hline Q Rovista Dialectus & Ano 5 & n. 12 & Janeiro - Julho 2018 & p. $419-438$ \\
\hline
\end{tabular}


consiste na leitura desenvolvimental, a qual entende a imanência em termos de desenvolvimento interno do conceito. ${ }^{36}$

De acordo com essa leitura da Lógica, a Lógica Subjetiva não é apenas uma parte (mesmo que a mais sofisticada) do todo, mas tem um caráter universal, na medida em que incorpora ou, como Hegel diz, reproduz (Enc. $\$ 171$ Observação) ${ }^{37}$, o conteúdo da Lógica Objetiva, trazendo-o a um estágio de conceituação mais explícita ('para si') e concreta. Por conseguinte, o compreender (Begreifen) não é uma condição de possibilidade de toda a ciência, mas antes o único sujeito e objeto dela. O sujeito da Lógica não deve ser confundido com um portador estável de acidentes, de acordo com as pressuposições de uma ontologia proposicional. O compreender é a identidade de método e conteúdo, na qual o conceito se resolve no processo ininterrupto de sua apresentação, de sua forma mais imediata (ser puro) a sua forma mais concreta (ser como razão ou Ideia).

O conceito da Lógica deveria ser comparado com a enérgeia de Aristóteles $^{38}$, porque, em ambos os casos, trata-se de uma atividade em que início e fim coincidem, de modo que a diferença temporal entre passado e presente se torna irrelevante, ou, em termos hegelianos, resulta suprassumida. Por causa disso, a transição da Lógica Objetiva para a Lógica Subjetiva resulta ser uma autodiferenciação do conceito, ou melhor, uma progressão do estágio em que o conceito está presente em si (Lógica Objetiva) para o estágio em que o conceito se reconhece como o resultado de seu movimento (Lógica Subjetiva). A relação entre Lógica Objetiva e Lógica Subjetiva é circular, no sentido de que a primeira é a segunda em potência, enquanto que a segunda é a explicitação consumada da primeira. Essa relação configura um

36 Sobre a leitura desenvolvimental da Lógica, ver: GIUSPOLI, P. "Objektive und Subjektive Logik. Über die allgemeine Organisation der Hegelschen Logik in den ersten Nürnberger Jahren". HegelStudien. Hamburg: Meiner, 35, 2000, pp. 77-106; SCHÄFER, R. Die Dialektik und ihre besonderen Formen in Hegels Logik. "Hegel-Studien", Beiheft 45. Hamburg: Meiner, 2001, p. 314; KERVÉGAN, J.F. "La science de l'idée pure", Archives de Philosophie. Paris: n. 75, 2012, pp. 199-215, part. pp.212-214.

37 HEGEL (1995) p. 306: "Em relação às duas esferas precedentes, do ser e da essência, os conceitos determinados são, enquanto juízos, reproduções dessas esferas, mas postas na relação simples do conceito."

38 Cf. FERRARIN (2016) p. 97: "La grandezza di Aristotele secondo Hegel è non tanto di averci illustrato questi caratteri dell'attività che chiama poiesi e che sono gli stessi di ogni movimento che è per essenza incompiuto, quanto soprattutto di averci additato il modello alternativo dell'energeia compiuta. In questa, che regola tanto il pensare quanto la prassi umana nell'indifferenziazione di passato e presente, non abbiamo un diventare altro ma uno sviluppo di sé, in cui il soggetto del movimento e il suo fine coincidono (il soggetto è archē kai telos), così come coincidono, o smettono di valere per la loro differenza, inizio e fine."

\begin{tabular}{|c|c|c|c|c|}
\hline Qevista Dialectus & Ano 5 & n. 12 & Janeiro - Julho 2018 & p. $419-438$ \\
\hline
\end{tabular}


contrachoque ou uma reviravolta metódica, porque, embora apareça que o ser e a essência tenham produzido o conceito, eles são, na verdade, os momentos mais abstratos da autoprodução do conceito. O 'contrachoque' da Lógica consiste no fato de que o conceito não é o primeiro, mas chega a ser o primeiro na medida em que, no final, através da reflexão filosófica, descobre a si mesmo como um processo de geração, único e universal, em que ser e agir são um e o mesmo. O conceito não é uma entidade já pronta que preordenaria as regras do pensamento de acordo com uma teleologia externa, mas antes o automovimento do elemento lógico enquanto caracterizado por uma finalidade interna. A ênfase de Hegel sobre o "princípio lógico como elemento" 39 quer dizer que o conceito é uma atividade imanente às suas formas, não um fundamento ou uma causa (eficiente ou final) que se mantenha distinta delas.

\section{Conclusão}

Gostaria de concluir com uma breve explicitação das tarefas e dos caracteres da peculiar lógica ontológica de Hegel. Desta maneira, as pressuposições da interpretação de Redding se destacam como outros tantos limites da leitura neotranscendental da Lógica de Hegel.

Em primeiro lugar, a ontologia ou teoria do ser é, para Hegel, uma disciplina dogmática na medida em que pressupõe ou toma como garantido que haveria um isomorfismo ingênuo entre pensamento, ou linguagem, e realidade. Uma vez que o filosofo alemão quer tomar distância dessa pressuposição inerente à 'Primeira posição do pensamento a respeito da objetividade', ele usa o termo 'ontologia' em um sentido exclusivamente crítico, mas não para qualificar positivamente seu projeto especulativo.

Em segundo lugar, se a identidade do ser e do pensar não pode ser uma mera pressuposição, ela tem que ser provada. Essa prova se realiza, de modo negativo, na Fenomenologia do Espírito; de modo positivo, na Lógica. ${ }^{40}$

Em terceiro lugar, o método da prova da identidade do ser e do pensar não é hipotético-dedutivo ou linear, mas é um processo sistemático articulado em dois caminhos: o caminho de acesso ao sistema, que fornece a prova cética da filosofia especulativa para os pontos de vista não especulativos (a Fenomenologia), e o caminho

${ }^{39}$ HEGEL (2016) p. 63.

40 Considerado que a 'prova' hegeliana remete a uma autocrítica do pensamento, não concordo com a tese de Halbig de que a coincidência de ser e pensar, de lógica e metafísica, seria uma "premissa metafísica" do idealismo absoluto de Hegel. Cf. HALBIG (2002) pp.370-71.

\begin{tabular}{|c|c|c|c|c|}
\hline Revista Qialectus & Ano 5 & n. 12 & Janeiro - Julho 2018 & p. $419-438$ \\
\hline
\end{tabular}


de atravessamento do próprio sistema, que constitui a apresentação da relação reflexiva de natureza e espírito através da mediação do elemento lógico enquanto princípio da identidade silogística de seus extremos (Enciclopédia).

Em quarto lugar, a especulação incorpora o momento cético, na medida em que neutraliza o dilema entre a tese do realismo metafísico ("o mundo é independente do pensamento") e a tese do idealismo subjetivo ("o mundo depende do pensamento"). O idealismo de Hegel é absoluto na medida em que não é uma teoria sobre o pensar objetivo, mas, antes, é a apresentação do processo pelo qual o pensar objetivo chega a se reconhecer como a razão de ser de tudo o que há.

Em quinto lugar, o projeto hegeliano de uma crítica imanente do pensar não pode ter um caráter transcendental, porque a filosofia transcendental está comprometida com um conjunto de pressuposições sobre o pensar e sobre o ser que não são capazes de resistir a um exame radicalmente cético.

Em sexto lugar, a interpretação de Redding relativa à maneira em que Hegel entende a identidade de ser e pensar está comprometida com as pressuposições de uma filosofia transcendental de tipo pragmatista. Por conseguinte, ela perde de vista o elemento distintivamente idealista da fundamentação hegeliana do conteúdo e do método de uma metafísica autocrítica.

\section{REFERÊNCIAS}

BORDIGNON, M. Ai limiti della verità. Il problema della contraddizione nella logica di Hegel. Pisa: ETS, 2014.

BRANDOM, R. "Hegel e a filosofia analítica". Veritas. Porto Alegre: v.56, n.1, 2011, pp.78-94.

BRINKMANN, K. Idealism without Limits. Hegel and the Problem of Objectivity. Dordrecht-New York: Springer, 2010.

CORTI, L. Ritratti hegeliani. Un capitolo della filosofia americana contemporanea. Roma: Carocci, 2014.

DÜSING, K. Hegel e l’antichità classica. Napoli: Città del Sole, 1998. "Grundformen der Ontologie bei Kant und bei Hegel”, Quaestio, 9 (2009), pp.311-324.

FERRARIN, A. Il pensare e l'io. Hegel e la critica di Kant. Roma: Carocci, 2016.

FORSTER, M. Hegel and Skepticism. Cambridge: Harvard University Press, 1989.

\begin{tabular}{|l|l|l|l|l|}
\hline Gevista Qialectus & Ano 5 & n. 12 & Janeiro - Julho 2018 & p. 419-438 \\
\hline
\end{tabular}


GIUSPOLI, P. “Objektive und Subjektive Logik. Über die allgemeine Organisation der Hegelschen Logik in den ersten Nürnberger Jahren". Hegel-Studien. Hamburg: Meiner, 35, 2000, pp. 77-106.

HALBIG, C. Objektives Denken. Erkenntnistheorie und Philosophy of Mind in Hegels System, Stuttgart - Bad Canstatt, 2002.

HARTMANN, K. "Hegel: A Non-Metaphysical View". Em: Hegel: A Collection of Critical Essays. MacIntyre A. (Org.). Notre Dame: Notre Dame Press, 1972, pp. 101124.

HEGEL, G.W.F. Enciclopédia das Ciências Filosóficas em Compêndio (1830). Vol. I: A Ciência da Lógica (tradução de Paulo Meneses). São Paulo: Edições Loyola, 1995.

HEGEL, G.W.F. Ciência da Lógica. 1. A Doutrina do Ser. Petrópolis: Vozes, 2016.

HEIDEMANN, D. Der Begriff des Skeptizismus. New York: De Gruyter, 2007.

HOUlGATE, S. The Opening of Hegel's Logic. Indiana: Purdue University Press, 2006.

IBER \& ORSINI \& NARDI \& BAVARESCO. "Teoria do juízo na lógica do conceito de Hegel”. Revista Opinião Filosófica, Porto Alegre, v. 06; nº. 01, 2015, pp. 34-48.

ILLETTERATI, L. (Org.) L'oggettività del pensiero. La filosofia di Hegel tra idealismo, anti-idealismo e realismo. Trento: Verifiche, 36, 2007.

KERVÉGAN, J.F. "La science de l'idée pure”. Archives de Philosophie. Paris: n. 75, 2012, pp. 199-215.

LAU, C.-F. "The Aristotelian-Kantian and Hegelian Approaches to Categories". The Owl of Minerva, 40:1 (2008-2009), pp.77-114.

LONGUENESSE, B. Hegel and the Critique of Metaphysics. translated by Nicole J. Simek. Cambridge: Cambridge University Press, 2007.

NUZZO, A. (Org.) Hegel and the Analytic Tradition. New York: Continuum, 2009.

ORSINI, F. A Teoria Hegeliana do Silogismo. Tradução e Comentário. Porto Alegre: Editora Fi, 2016.

"O projeto hegeliano de uma filosofia livre de pressuposições" (artigo aceito para a publicação pela revista Kriterion).

PIPPIN, R. Hegel's Idealism. The Satisfactions of Self-Consciousness. Cambridge: Cambridge University Press, 1989.

\begin{tabular}{|l|l|l|l|l|}
\hline Q Povista Dialectus & Ano 5 & n. 12 & Janeiro - Julho 2018 & p. 419-438 \\
\hline
\end{tabular}


PINKARD, T. "The Logic of Hegel's Logic". The Journal of the History of Philosophy, 17, 1979, pp. 417-435.

REDDING, P. Analytic Philosophy and the Return of Hegelian Thought. Cambridge: Cambridge University Press, 2007.

The Relation of Logic to Ontology in Hegel, in Categories and

Being. Essays on Metaphysics and Logic, eds. L.Haaparanta and J.Koskinen, Oxford University Press, 2012, pp.145-166.

SCHÄFER, R. Die Dialektik und ihre besonderen Formen in Hegels Logik. "HegelStudien”, Beiheft 45. Hamburg: Meiner, 2001.

TRISOKKAS. I. Pyrrhonian Skepticism and Hegel's Theory of Judgment. Leiden: Brill, 2012.

\begin{tabular}{|l|l|l|l|l|}
\hline Q & Dovista \\
\hline
\end{tabular}

